\title{
Translation and Adaptation of the Social Connectedness Scale to Portuguese
}

\author{
André L. A. Rabelo \\ Ronaldo Pilati ${ }^{1}$ \\ ${ }^{1}$ Universidade de Brasilia, Brasilia, Distrito Federal, Brasil
}

\begin{abstract}
The goal of the present study was to adapt the social connectedness scale (SCS) to Brazilian Portuguese and evaluate its psychometric properties. A survey was conducted with 222 participants. They answered the SCS, the positive and negative affective schedule (PANAS), the Duke University Religion Index (DUREL), two pictorial measures of social connectedness, and a sociodemographic questionnaire. The original one factor solution was supported by the data. The SCS-derived score was significantly associated with the other measures in the expected directions. The results described in the present study are favorable regarding the internal consistency and evidence of validity of SCS scores. The study offers three social connectedness measures that can be used to investigate the impacts of social connectedness on cognition, behavior and health of Brazilians.

Keywords: social connectedness; interpersonal relationships; religion; affection
\end{abstract}

\section{Tradução e Adaptação da Escala de Conectividade Social para o Português}

\begin{abstract}
Resumo
O objetivo do presente estudo foi adaptar a Escala de Conectividade Social (SCS) para o português brasileiro e avaliar suas propriedades psicométricas. Um levantamento de dados foi realizado com 222 participantes. Eles responderam à SCS, o Positive and Negative Affective Schedule (PANAS), o Índice de Religião da Duke University (DUREL), duas medidas pictóricas de conectividade social e um questionário sociodemográfico. A solução original de um fator foi apoiada pelos dados. O escore derivado da SCS esteve significativamente associado com as outras medidas nas direções esperadas. Os resultados descritos no presente estudo são favoráveis quanto à consistência interna e à evidência de validade dos escores da SCS. O estudo oferece três medidas de conectividade social que poderão ser usadas para investigar os impactos da conectividade social na cognição, comportamento e saúde dos brasileiros.
\end{abstract}

Palavras-chave: conectividade social, relações interpessoais, religião, afeição

\section{Traducción y Adaptación de la Escala de Conectividad Social para el Portugués}

\begin{abstract}
Resumen
El objetivo del presente estudio fue adaptar la escala de conectividad social (SCS) para el portugués brasileño y evaluar sus propiedades psicométricas. Se realizó una encuesta de datos con 222 participantes. La muestra respondió al SCS, el positive and negative affective schedule (PANAS), el Índice de Religión de la Universidad de Duke (DUREL), dos medidas pictóricas de conectividad social, además de un cuestionario sociodemográfico. La solución original de un factor fue respaldada por los datos. Los resultados derivados de la SCS se asociaron significativamente con las otras medidas en las direcciones esperadas. Los resultados descritos en el presente estudio son favorables con respecto a la consistencia interna y la evidencia de validez de los escores de la SCS. El estudio ofrece tres medidas de conectividad social que se pueden utilizar para investigar los impactos de la conectividad social en la cognición, el comportamiento y la salud de los brasileños.

Palabras clave: conectividad social; relaciones interpersonales; religión; afección
\end{abstract}

Significant relationships are not only pleasing, useful, and fun to have, but can also considerably improve (or damage) people's lives. They are essential for adapting to complex social environments, and different scientists argue that our ability to form these relationships through large scale cooperative groups may have strongly shaped the cultural and biological evolution of our species (Tomasello, 2014). Knowledge about social relationships' role in our lives has been increasing in the last decades due to scientific efforts around the world to uncover the causes and consequences of having (or lacking) positive social relationships in our daily lives. Different studies have been showing that social bonds can strongly influence different aspects of people's health, well-being, cognition, and behavior (Brown, Gallagher, \& Creaven, 2018; Holt-Lunstad, 2018; Howell et al., 2014).

One extreme example of this comes from a meta-analysis that included data from 148 independent studies and demonstrated that having meaningful social relationships can strongly predict mortality in a magnitude that is comparable to widely known risk factors such as smoking (Holt-Lunstad, Smith, \& Layton, 2010) or obesity (Holt-Lunstad, 2018). Apparently, people nurturing greater and healthier relationships seems to live longer then those that are more socially isolated. 
Other studies have showed more specific associations of higher social connectedness with higher personal growth (Lee, Ybarra, Gonzalez, \& Ellsworth, 2018), lower depression (Cruwys, Haslam, Dingle, Haslam, \& Jetten, 2014), and higher well-being (Sun, Harris, \& Vazire, 2019).

Some theories hold that social relationships are so central to humans that they share a universal basic motivation to cultivate long-lasting and positive relationships known as the need to belong or affiliative motive (Pillow, Malone, \& Hale, 2015), and failing to satisfy this need may predispose people to depression and other health-related problems (Cacioppo, Cacioppo, Capitanio, \& Cole, 2015). Social connectedness can be defined as a subjective sense of connection with one's social world (R. M. Lee \& Robbins, 1995) and experiencing it through meaningful relationships can be associated with an array of benefits such as increased happiness, well-being, and positive affect (Kok et al., 2013; R. M. Lee, Dean, \& Jung, 2008; R. M. Lee \& Robbins, 1998; Mauss et al., 2011).

A better understanding of social connectedness' antecedents and mechanisms of influence in different cultures can help psychologists to develop more sophisticated theories about how social relationships influence people in different contexts and to promote happiness and health in society through interventions that take the phenomenon's complexities into account. Despite its importance, social connectedness has barely been investigated in many countries such as Brazil. There is no measure of social connectedness available for Brazilian researchers interested in this topic, which represents a main obstacle to the systematic investigation of this phenomenon and its potential particularities in this culture. The main goal of the present study was to adapt the social connectedness scale (SCS) to Brazilian Portuguese and evaluate its psychometric properties. To reach this goal, evidence of validity will be estimated by a confirmatory factor analysis and by describing the associations between social connectedness, affect, and religiosity, which are previously known correlates of social connectedness as will be described ahead.

One of the first measures of social connectedness to be developed was the social connectedness scale by Lee and Robbins (1995) and later revised (R. M. Lee, Draper, \& Lee, 2001). The original scale is composed of 8 items and all of them were negatively worded, that is, indicating a lack of social connectedness. Participants should choose one of six response options varying from $1=$ strongly agree to $6=$ strongly disagree. The revised social connectedness scale, which is a revision of the social connectedness scale, is composed of 20 items: 10 positively worded and 10 negatively worded. The scale presented acceptable reliability $(a=.94)$, significant correlations with the UCLA loneliness scale $(r$ $=-.80)$, membership $(r=.49)$, private $(r=.42)$, and public self-esteem $(r=.39)$ as evidence of discriminant validity. They also found statistically significant correlations of the scale with independent self-construal $(r=$ $.37)$, social avoidance $(r=-.57)$ and social distress $(r$ $=-.55)$. One problem with this measure is that it was based on an operational definition of social connectedness that is not explicitly described, making the task of critically evaluating its underlying conceptual logic difficult.

A more recent measure of social connectedness (SCS) was developed by Lambert et al. (2013). According to these authors, it captures the subjective experience of belonging, that is, a sense of having positive and meaningful relationships. The scale is composed of seven items and two items are negatively worded. Participants must choose one of five response options varying from completely agree to completely disagree. The scale presented acceptable evidence of internal consistency $(a=$ .81). The authors also reported a significant correlation of the SCS with the UCLA loneliness scale $(r=-.54)$ as evidence of discriminant validity and a correlation with self-esteem $(r=.64)$ as evidence of convergent validity.

Both social connectedness scales have similar item formats, response scales, and favorable evidence regarding their psychometric properties. The fact that the scale from Lambert et al. (2013) is more recent, shorter, mainly composed of positively worded items, which makes the instrument less ambiguous, and explicitly describes the conceptual definition upon which the instrument was based makes it a preferable option for adapting to Brazil. The definition underlying the scale is especially important because many terms used in this literature, such as belong, have no direct and equivalent literal translation in Brazilian Portuguese. In such a case, the definition will be crucial during the adaptation process because it will guide the judgment about adaptations that may be necessary to apply.

The validity of the SCS will be evaluated in terms of its dimensionality and relationships with other related measures. Previous studies have shown that social connectedness is associated with being religious and greater religiosity, that is, the degree of dedication to a religion's habits, rituals, and conventions (Azagba, Asbridge, \& Langille, 2014; Houltberg, Henry, Merten, 
\& Robinson, 2011). For example, one study showed that Christians tended to exhibit more happiness and social connectedness than atheists based on the content of their tweets (Ritter, Preston, \& Hernandez, 2013). Social connectedness partially mediated the relationship between religiosity and happiness in this study, indicating that at least some of religiosity's influence on important constructs such as happiness (Bixter, 2015) can come about through an increased level of social connectedness. Higher social connectedness' levels are also associated with greater positive affect, lower negative affect, and well-being (Holt-Lunstad, 2018; Mauss et al., 2011; Seppala, Rossomando, \& Doty, 2008; Sun et al., 2019). For these reasons, the relationships between social connectedness, affect, and religiosity will be used to evaluate the validity of scores generated from the Portuguese version of the SCS, which will help to achieve an important part of this study's goal.

Another way of testing this measure's validity is by estimating its association with other measurement procedures aimed at measuring social connectedness too. In principle, different measurement procedures developed to measure social connectedness should be strongly related. Two versions of a pictorial measure of social connectedness inspired by the pictorial measures of self-categorization developed by Schubert and Otten (2002) were included in the present study with two purposes: evaluating the relationship between selfreport and pictorial measurement procedures of social connectedness and the impact of the specificity of the targets of social connectedness in the SCS's items.

The comparison of the relationships between these two pictorial measures with the SCS can help clarifying what exactly is the SCS measuring, considering that the targets in the items of this measure varies considerably (i.e. ranging from feeling connected to "family" to "others"). One of these pictorial measures is focused on members of a person's closest ingroups (i.e. family and friends) while the other is focused on unknown people. A larger correlation with one of these pictorial measures in comparison to the other will show what construct is better captured by the SCS - a more general feeling of social connectedness not related to specific targets or a feeling especially directed at ingroup members. At the same time, observing a similar level of association with both pictorial measures will indicate that SCS may work as a general measure of social connectedness that is similarly focused on different potential targets of social connectedness and not only on ingroup members.
This comparison is especially important given recent discussions in the literature about the dimensionality of social connectedness. Hirsch and Clark (2019), for example, have recently highlighted the fact that psychologists have traditionally treated social connectedness as a unidimensional construct despite the accumulating evidence in favor of its multidimensional nature. According to these authors, people achieve social connectedness through at least four paths: the communal-relationship path, the generalapprobation path, the group-membership path, and the minor-sociability path. In real life, people are constantly varying the degree to which they experience social connectedness through these different paths and, during their interactions, the different paths can have additive, substitutive or conflicting effects with one another on people's cognition, behavior, and health, although these interactions still demand further exploration by future studies and the present study may offer a useful tool for Brazilian psychologists interested in exploring the complexities surrounding social connectedness.

\section{Method}

\section{Participants}

In the sample of 222 participants, the mean age was 33.6 years $(S D=13.41)$ and most of the participants were woman $(\mathrm{N}=175)$. Most of the participants were religiously affiliated with Spiritism $(\mathrm{N}=49)$, Catholicism $(\mathrm{N}=41)$, to a religion that was not mentioned $(\mathrm{N}=31)$ or no religion $(\mathrm{N}=50)$ (Agnosticism: 19, Buddhism: 13, Protestant: 7, Atheism: 6, AfroBrazilian religions: 4, Jewish: 2). The initial estimation of the sample size was made by performing a power analysis through the pwr package of the $\mathrm{R}$ language and computational environment ( $\mathrm{R}$ Core Team, 2019). To obtain a power of .80 with an alpha value of .05 and at least an expected low effect size (.20) for a correlation test, 194 participants were a minimal sample size.

\section{Instruments}

We adapted the social connectedness scale (SCS) to Brazilian Portuguese (see Appendix). It is composed of seven items developed by Lambert et al. (2013) and the scale is associated to a five-point Likert scale, varying from "discordo totalmente" (completely disagree) to "concordo totalmente" (completely agree) (i.e. "I feel like there are many people with whom I belong", "I really feel accepted by others in my life"). Two researchers in 
the field of social psychology that fluently speak Portuguese and English were involved in the application of the back-translation method. One of them made an initial translation and the other one back-translated the translated version. The back-translated version was compared with the original one for adjustments. A professional translator with fluency in Portuguese and English also translated the instrument. Both the back translation of the researcher and the translation of the professional translator were used as comparisons to seek for improvements.

The word "belong" does not have a clear and unambiguous correspondent in the Brazilian Portuguese language. The most literal translation of this word would be "pertencer" (verb) or "pertencimento" (noun), which are poorly used words in ordinary language and even less used to refer to the subjective experience of having positive and meaningful relationships. A word that is much more used in ordinary language to refer to this kind of experience is "vinculo" and "vinculo afetivo" - something like, respectively, "bond" and "affective bond" in English. We found convergent evidence for this translation in articles written in Portuguese about self-determination theory, which also have translated the need of relatedness proposed by this theory as the need of "vinculo social" - something similar to "social bond" in English (Appel-Silva, Wendt, Argimon, Iracema, \& Argimon, 2010).

Another convergent evidence for this translation comes from the Portuguese translation of an important book on the subject of social connectedness and loneliness (Cacioppo \& Patrick, 2011). Social connectedness/social connection was translated in the book as "vinculo social". But "vinculo social" is not a common expression in ordinary language. On the other hand, "vinculo" and "vínculo afetivo" are very commonly used expressions in ordinary language to express or describe a feeling of connection and closeness to another person or group. For example, the expression "vinculo terapêutico" (therapeutic bond), which is a common expression in clinical psychology, refers to the affective bond between a patient and his or her psychotherapist. Considering these reasons, social connectedness and belong were translated as some variation of "vinculo afetivo". The use of "vinculo afetivo" is preferable to "vinculo social" in the items because it is an expression commonly used in ordinary language, making it less ambiguous for participants.

The Portuguese version (Carvalho et al., 2013) of the positive and negative affective schedule
(PANAS) was used. The scale is composed of 19 items describing nine positive and ten negative affective states. Participants must inform the extent to which they experienced each affective state within a general time frame. Answers are given using a 5-point Likert scale varying from "very slightly or not at all" to "very much". Fit indices obtained through a confirmatory factor analysis adopting maximum likelihood, assuming an orthogonal two-factor solution, and implemented by the lavaan package were mostly acceptable $\left(\chi^{2}=428.8, d f=151, p<.001 ;\right.$ CFI $=.85$; TLI $=.84$; SRMR $=.08$ RMSEA $=.09$ (CI 90\%: .08$.10), p<.001)$. Two mean scores were computed, and both the positive and negative affect scores exhibited acceptable levels of internal consistency ( $a=.88$ for both scores).

Participants' religiosity was measured by means of the Portuguese version (Moreira-Almeida, Peres, Aloe, Lotufo Neto, \& Koenig, 2008) of the Duke University Religion Index (DUREL). This is a five-item multidimensional scale the captures three dimensions of religiosity: organizational religiosity (OR) refers to the frequency of engaging in religious meetings, nonorganizational religiosity (NOR) refers to the frequency of engaging in private religious activities, and intrinsic religiosity (IR) is related to a person's search for living his or her religiosity as a main life goal. Participants must answer the OR item through a six-point scale (varying from "Never" (1) to "More than once/week" (6)) the NOR item through another six-point scale (varying from "Rarely or never" (1) to "More than once a day" (6)), and the IR items through a five-point scale (varying from "Definitely not true" (1) to "Definitely true of me" (5)). The original authors do not recommend synthesizing the measure in one score. Instead, the first item should be treated as the OR score, the second item should be treated as the NOR score, and a mean score of IR should be computed with the three remaining items. The internal consistency of the IR dimension was acceptable $(a=.79)$.

As an additional way of testing the validity of the scores derived from the SCS, we included in the study two variations of a measure of Overlap of Self, Ingroup, and Outgroup (OSIO) (Schubert \& Otten, 2002), which is a measure of how the self is perceived in the intergroup realm. The ingroup version (IN) asked participants to choose one picture among seven options that best described how close they were to their parents and close friends. The seven pictures exhibited two circles that were increasingly close until they 
started to physically overlap and finally one circle was entirely inside the other one in the last response option. The circle in the left represented the "self" and it was smaller than the circle in the right, which represented "parents and close friends". The outgroup version (OUT) was very like the first one. The only difference was that instead of "parents and close friends" being the label for the bigger circle in the right, the OUT had "unknown people" as the label.

The IN should have a medium to large positive association with social connectedness as it measures how close people perceive themselves to the likely most significant ingroup that people usually have - that is, friends and family. We also expected a low to medium positive association of the OUT with social connectedness as this version measures how close people perceive themselves to a less likely target of strong social connectedness. Yet people with high levels of social connectedness could have higher scores in both versions, while people extremely disconnected will probably have lower scores in both measures. Finally, a socio-demographic questionnaire was used to measure participant's sex, age, and religious affiliation. A variable called "religious" was computed based on participants' self-reported religious affiliation and it was composed of three levels: religious (Spiritism, Catholicism, Protestant, Afro-Brazilian religions, Buddhism, and Jewish), nonreligious (Atheism and Agnosticism), and others (those who reported having no religion or one that was not mentioned).

\section{Procedure}

The research was conducted on the internet by means of the EFS Survey software. Participants were initially presented to an informed consent form emphasizing that the participation was anonymous, voluntary, and that the participant could end his or her participation at any time without any potential harm associated with it. If participants agreed with the form and explicitly indicated that by clicking in a digital button, they were directed to answer the SCS, the PANAS, the OSIO versions, the DUREL, and a socio-demographic questionnaire. After this, participants were thanked and an email for contact was made available in the final page. The items of each scale were presented in a random order to decrease the probability of order effects. The studies reported here strictly followed the Ethical Principles in the Conduct of Research with Human Participants proposed by the American Psychological Association.

\section{Results}

Statistical analyses were performed using the $\mathrm{R}$ language and computational environment. Fit indices obtained through a confirmatory factor analysis of the social connectedness scale (SCS) adopting the Weighted Least Squares Mean and Variance-Adjusted (WLSMV) estimation method, assuming a one-factor solution, and implemented using the lavaan package were acceptable $\left(\chi^{2}=30.5, d f=14, p=.006 ;\right.$ CFI $=.96 ;$ TLI $=.94$; SRMR $=.08$, RMSEA $=.07$ (CI 90\%: .04-.11), $p<$ .001). The items' scores presented acceptable levels of internal consistency $(a=.77 ; \omega=.85)$ and one mean score (SC) was computed (higher values indicating greater levels of self-reported social connectedness).

Both the Shapiro-Wilk test, histograms, values of kurtosis, and skewness indicated that many of the main variables (SC, positive affect $(\mathrm{PA})$, negative affect $(\mathrm{NA})$, ingroup version of the OSIO (IN), outgroup version of the OSIO (OUT), intrinsic religiosity (IR), organizational religiosity (OR), nonorganizational religiosity (NOR)) deviated considerably from a normal distribution as can be seen in Figure 1. For this reason, Spearman's rho was adopted to estimate the associations between the scores, and they can be visualized in Table 1.

SC was positively associated with PA while negatively associated with NA. Both coefficients were statistically significant and represented medium-sized levels of association. PA and NA presented a negative, statistically significant, and medium to large magnitude of association. SC exhibited a statistically significant association with both the IN and OUT, but while the association with IN was large-sized, the one with OUT was medium-sized. IN and OUT were also significantly associated with one another as evidenced by a mediumsized coefficient. A negative, statistically significant, and low to medium-sized coefficient of association was observed between IR and SC. The religiosity dimensions were significantly associated with one another and both NOR and IR presented a negative, significant association with PA.

Figure 2 shows a comparison between being religious and feeling socially connected. The three religious' groups (religious, nonreligious, and others) presented similar levels of SC and OUT. While religious participants exhibited a slightly higher level of SC, nonreligious participants exhibited a slightly higher level of social connectedness in the OUT score. In the IN score, religious participants showed more social connectedness than the other two groups, but 

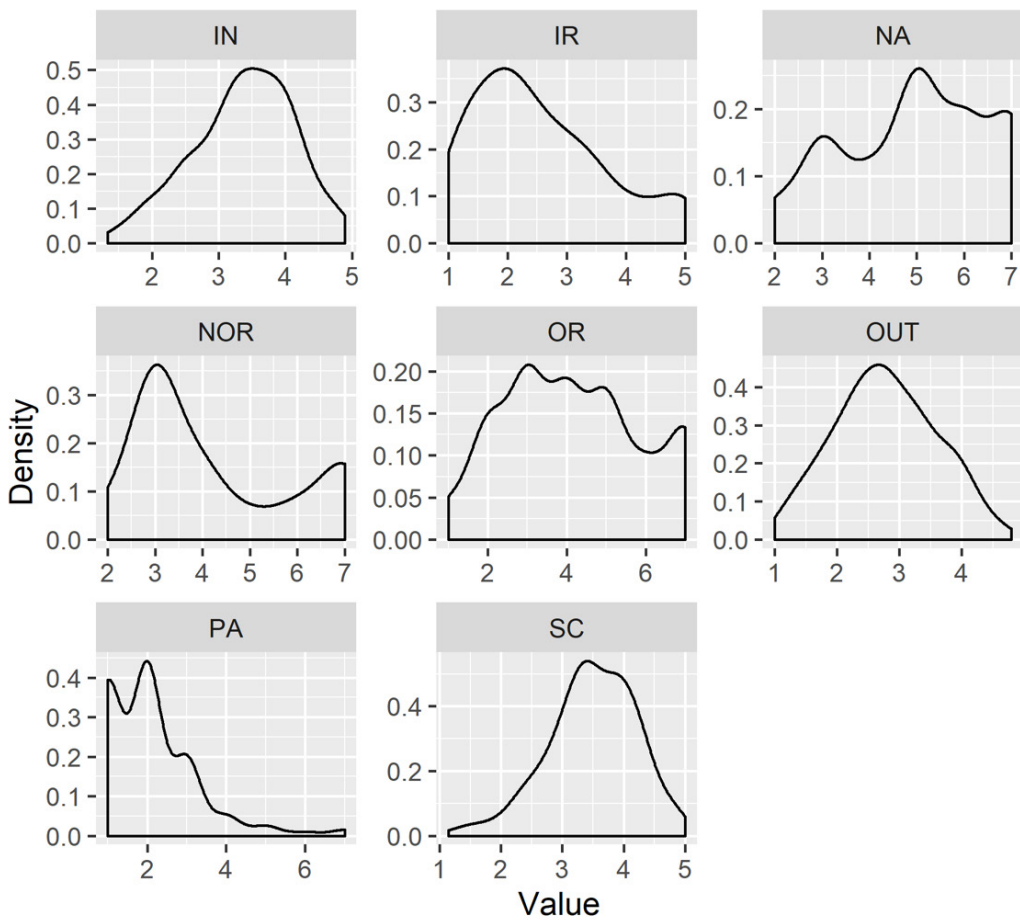

Figure 1. Distributions of the main variables.

Table 1.

Means, Standard Deviations (SD), and Spearman's Rho for Relationships Between the Main Variables

\begin{tabular}{ccccccccc}
\hline Variable & Mean $(\mathrm{SD})$ & 1 & 2 & 3 & 4 & 5 & 6 & 7 \\
\hline & & & & & & & & \\
1. SC & $3.48(.72)$ & & & & & & & \\
2. PA & $3.36(.77)$ & $.39 * *$ & & & & & & \\
3. NA & $2.78(.82)$ & $-.34^{* *}$ & $-.41^{* *}$ & & & & & \\
4. IN & $4.15(1.74)$ & $.49^{* *}$ & $.22^{* *}$ & -.10 & & & & \\
5. OUT & $2.09(1.18)$ & $.30^{* *}$ & .13 & -.04 & $.36^{* *}$ & & & \\
6. OR & $4.96(1.53)$ & -.08 & -.12 & .07 & -.12 & $>.001$ & & \\
7. NOR & $4.21(1.67)$ & -.06 & $-.25^{* *}$ & .09 & -.07 & -.06 & $.38^{* *}$ & \\
8. IR & $2.56(1.13)$ & $-.20^{*}$ & $-.25^{* *}$ & $.16^{*}$ & $-.16^{*}$ & $-.14^{*}$ & $.42^{* *}$ & $.48^{* *}$ \\
\hline
\end{tabular}

Note. $*$ indicates $p<.05 ; * *$ indicates $p<.01$.

this difference was not statistically significant and was associated with a low effect size according to a KruskalWallis test $\left(\chi^{2}=4.79, d f=2, p=.09, \varepsilon^{2}=.02\right)$.

\section{Discussion}

Nurturing positive, meaningful, and healthy social relationships has been shown to predict not only different aspects of people's health, cognition, and behavior, but even how long they live (Holt-Lunstad et al., 2010). Such relationships are vital and adaptive to human beings as it is to many other social organisms (Tomasello, 2014). Unfortunately, until now, there was no psychological instrument available to Brazilian psychologists interested in studying the impacts of experiencing social connectedness on psychological 


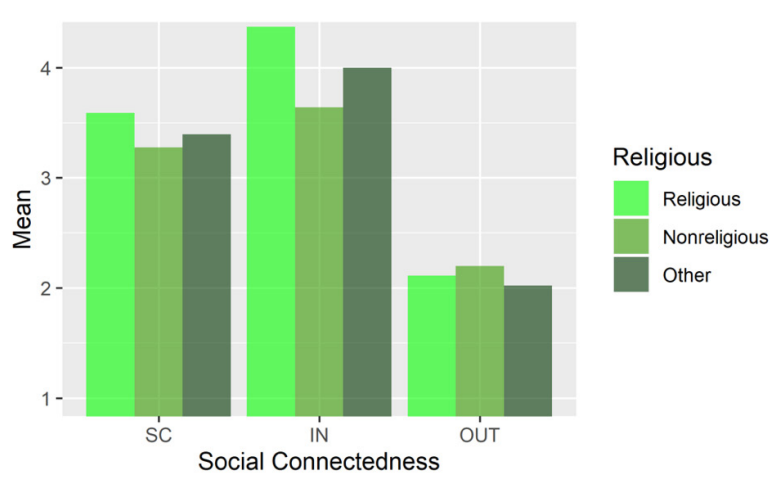

Figure 2. Differences in social connectedness indicators (social connectedness (SC), ingroup version (IN), outgroup version (OUT)) among religious, nonreligious, and other participants.

processes. The present study described the translation and adaptation of the social connectedness scale (SCS) to Brazilian Portuguese. Evidence for validity and internal consistency were favorable and the original one-factor solution was supported by a confirmatory factor analysis (Lambert et al., 2013).

SC was consistently and significantly associated with almost all variables included in the study, except for two religious' dimensions (OR and NOR) of the DUREL. The directions of the associations were coherent with previous expectations: SC was positively associated with PA, IN, and OUT, while negatively associated with NA, and IR. It is worth emphasizing that lower scores in IR indicate greater religiosity, so this association indeed corroborates previous findings (Azagba et al., 2014; Houltberg et al., 2011; Ritter et al., 2013). Nevertheless, comparing religious, nonreligious, and other participants by means of Kruskal-Wallis tests indicated that, although small mean differences could be observed in SC, IN, and OUT, they were not statistically significant and were associated with small effect sizes. As religious affiliations of the sample were considerably unbalanced, with the majority being religious, future studies could explore this matter with more balanced and religiously diverse samples.

The associations of social connectedness with PA and NA also corroborated findings from previous studies (Kok et al., 2013; R. M. Lee \& Robbins, 1998; Mauss et al., 2011). The comparison between the associations of SC with IN and OUT indicates that, although the SCS was designed to be a general social connectedness scale (Lambert et al., 2013), it was more strongly associated with the IN than the OUT. This means that, although many of the items are broad in scope ("I really feel accepted by others in my life"), the scale may be more related to social connectedness directed towards ingroup members and the items' contents are coherent with this conclusion. Some items are specific about the target of the feelings of social connectedness ("I feel a strong sense of belonging when I'm with my friends"), while others are broader, but still may be understood as referring to close people ("I feel like there are many people with whom I belong"). More extensive research is needed to better evaluate the scope of the feelings of social connectedness that the SCS is currently measuring. Nevertheless, the present study offers an important and innovative method of evaluating the construct validity of a social connectedness measure by using different versions of another instrument that vary in a relevant dimension (i.e. specificity of target) that is ambiguous in the SCS.

Another promising possibility is to develop multidimensional scales of social connectedness that can capture different sources of social connectedness in a more balanced and theoretically driven way. As proposed by Hirsch and Clark (2019), it is possible to achieve social connectedness in multiple ways and this distinction is normally disregarded in psychology. They present evidence that there are at least four paths to satisfying the need to belong: the communal-relationship path, the general-approbation path, the group-membership path, and the minor-sociability path. The distinction between these different paths is relevant because each one can have additive, substitutive or conflicting effects on other variables such as health when interacting with each other. This theoretical proposal is recent and new measures of social connectedness should consider these distinctions and further test their usefulness. The measure adapted in the present study may contribute to this by serving as one way of testing the convergent validity of new multidimensional measures with Brazilian samples.

One of the main contributions and implications of the present study is to make available three different instruments that can be used by Brazilian psychologists to measure social connectedness in different ways, possibly attending to different research purposes and demands: the social connectedness scale (SCS) (see Appendix) the OSIO ingroup version (IN), and the OSIO outgroup version (OUT) (Schubert \& Otten, 2002). The preliminary evidence presented here supports the use of these instruments, although limitations 
about them in the present study were highlighted. As this was the first study about social connectedness in Brazil, more studies exploring the relationship between the SCS with other variables and its psychometric properties are desirable.

The present study had some limitations. A bigger sample would be preferable to reach more conclusive evaluations of the quality of the SCS, but one widely used criterion for justifying sample size was applied power analysis - and the final sample in the present study was bigger than the one estimated by the power analysis. A predictive test of the SCS scores' validity could clarify the exact nature of its underlying construct and add another important source of evidence for validity. This could be made by including measures that social connectedness is already known to predict well in the study, such as measures of well-being, health, and mental health (Seppala et al., 2008; Sun et al., 2019). This is especially important considering the alarming conclusions that researchers have been making about the clinical dangers of lacking significant social relationships, which are comparable to the dangers of nicotine or obesity to health and longevity (Cacioppo \& Patrick, 2011; Cacioppo, Grippo, London, Goossens, \& Cacioppo, 2015).

The present study also relied mostly on selfreport measures and the SCS itself is a self-report measure. Indirect measurement methods such as pictorial (Schubert \& Otten, 2002) or implicit measures (Greenwald \& Banaji, 2017; Hofer, Busch, Raihala, Poláčková Šolcová, \& Tavel, 2017) could be more widely explored in the literature and add valuable information about how these constructs are mentally represented, to what extent people can easily be aware, and accurately report their social connectedness' levels. The IN and OUT are promising measurement methods to explore these issues, but additional methods, such as implicit measures, should also be developed in future studies. Comparing the relationship between the SCS' scores with scores derived from such indirect measurement methods could be a valuable source of evidence for validity that future studies should explore.

\section{References}

Appel-Silva, M., Wendt, G. W., Argimon, I. I. de L., Iracema, I., \& Argimon, D. L. (2010). A teoria da autodeterminação e as influências socioculturais sobre a identidade. Psicologia Em
Revista, 16(2), 351-369. Retrieved from http:// pepsic.bvsalud.org/scielo.php?script=sci_arttext\& pid $=$ S1677-11682010000200008

Azagba, S., Asbridge, M., \& Langille, D. B. (2014). Is religiosity positively associated with school connectedness: Evidence from high school students in atlantic Canada? The Journal of Primary Prevention, 35(6), 417-427. https://doi.org/10.1007/ s10935-014-0367-y

Bixter, M. T. (2015). Happiness, political orientation, and religiosity. Personality and Individual Differences, 72, 7-11. https://doi.org/10.1016/j.paid.2014.08.010

Brown, E. G., Gallagher, S., \& Creaven, A. M. (2018). Loneliness and acute stress reactivity: A systematic review of psychophysiological studies. Psychophysiology, 55(5), e13031. https://doi.org/10.1111/ psyp.13031

Cacioppo, J. T., Cacioppo, S., Capitanio, J. P., \& Cole, S. W. (2015). Neuroendocrinology of social isolation. Annual Review of Psychology, 66, 9.1-9.35. https:// doi.org/10.1146/annurev-psych-010814-015240

Cacioppo, J. T., \& Patrick, W. (2011). Solidão: A natureza bumana e a necessidade de vínculo social. Rio de Janeiro: Record.

Cacioppo, S., Grippo, A. J., London, S., Goossens, L., \& Cacioppo, J. T. (2015). Loneliness: Clinical import and interventions. Perspectives on Psychological Science, 10(2), 238-249. https://doi. org/10.1177/1745691615570616

Carvalho, H. W. De, Andreoli, S. B., Lara, D. R., Patrick, C. J., Quintana, M. I., Bressan, R. A., ... Jorge, M. R. (2013). Structural validity and reliability of the Positive and Negative Affect Schedule (PANAS): Evidence from a large Brazilian community sample. Revista Brasileira de Psiquiatria, 35(2), 169-172. https://doi.org/10.1590/1516-4446-2012-0957

Cruwys, T., Haslam, S. A., Dingle, G. A., Haslam, C., \& Jetten, J. (2014). Depression and social identity: An integrative review. Personality and Social Psychology Review, 18(3), 215-238. https://doi. org/10.1177/1088868314523839

Greenwald, A. G., \& Banaji, M. R. (2017). The implicit revolution: Reconceiving the relation between conscious and unconscious. American Psychologist, 72(9), 861-871. https://doi.org/10.1037/ amp0000238

Psico-USF, Bragança Paulista, v. 26, n. 1, p. 1-12, jan./mar. 2021 
Hirsch, J. L., \& Clark, M. S. (2019). Multiple paths to belonging that we should study together. Perspectives on Psychological Science, 14(2), 238-255. https://doi. org/10.1177/1745691618803629

Hofer, J., Busch, H., Raihala, C., Poláčková Šolcová, I., \& Tavel, P. (2017). The higher your implicit affiliation-intimacy motive, the more loneliness can turn you into a social cynic: A cross-cultural study. Journal of Personality, 85(2), 179-191. https://doi. org/10.1111/jopy.12232

Holt-Lunstad, J. (2018). Why social relationships are important for physical health: A systems approach to understanding and modifying risk and protection. Annual Review of Psychology, 69(1), 437-458. https:/ / doi.org/10.1146/annurev-psych-122216-011902

Holt-Lunstad, J., Smith, T. B., \& Layton, J. B. (2010). Social relationships and mortality risk: A meta-analytic review. PLoS Medicine, 7(7), e1000316. https://doi.org/10.1371/journal.pmed.1000316

Houltberg, B. J., Henry, C. S., Merten, M. J., \& Robinson, L. C. (2011). Adolescents' perceptions of family connectedness, intrinsic religiosity, and depressed mood. Journal of Child and Family Studies, 20(1), 111-119. https://doi.org/10.1007/ s10826-010-9384-5

Howell, J. L., Koudenburg, N., Loschelder, D. D., Weston, D., Fransen, K., De Dominicis, S., ... Haslam, S. A. (2014). Happy but unhealthy: The relationship between social ties and health in an emerging network. European Journal of Social Psychology, 44(6), 612-621. https:// doi.org/10.1002/ ejsp.2030

Kok, B. E., Coffey, K. A., Cohn, M. A., Catalino, L. I., Vacharkulksemsuk, T., Algoe, S. B., ... Fredrickson, B. L. (2013). How positive emotions build physical health: Perceived positive social connections account for the upward spiral between positive emotions and vagal tone. Psychological Science, 24, 1123-1132. https://doi. org/10.1177/0956797612470827

Lambert, N. M., Stillman, T. F., Hicks, J. A., Kamble, S., Baumeister, R. F., \& Fincham, F. D. (2013). To belong is to matter: Sense of belonging enhances meaning in life. Personality and Social Psychology Bulletin, 39, 1418 -1427. https://doi. org/10.1177/0146167213499186

Lee, D. S., Ybarra, O., Gonzalez, R., \& Ellsworth, P. (2018). I-through-we: How supportive social relationships facilitate personal growth. Personality and Social Psychology Bulletin, 44(1), 37-48. https:// doi.org/10.1177/0146167217730371

Lee, R. M., Dean, B. L., \& Jung, K.-R. (2008). Social connectedness, extraversion, and subjective well-being: Testing a mediation model. Personality and Individual Differences, 45(5), 414-419. https://doi. org/10.1016/j.paid.2008.05.017

Lee, R. M., Draper, M., \& Lee, S. (2001). Social connectedness, dysfunctional interpersonal behaviors, and psychological distress: Testing a mediator model. Journal of Counseling Psychology, 48(3), 310-318. https://doi.org/10.1037/0022-0167.48.3.310

Lee, R. M., \& Robbins, S. B. (1995). Measuring belongingness: The Social Connectedness and the Social Assurance scales. Journal of Counseling Psychology, 42(2), 232-241. https://doi. org/10.1037//0022-0167.42.2.232

Lee, R. M., \& Robbins, S. B. (1998). The relationship between social connectedness and anxiety, self-esteem, and social identity. Journal of Counseling Psychology, 45(3), 338-345. https://doi. org/10.1037//0022-0167.45.3.338

Mauss, I. B., Shallcross, A. J., Troy, A. S., John, O. P., Ferrer, E., Wilhelm, F. H., \& Gross, J. J. (2011). Don't hide your happiness! Positive emotion dissociation, social connectedness, and psychological functioning. Journal of Personality and Social Psychology, 100, 738-748. https://doi.org/10.1037/a0022410

Moreira-Almeida, A., Peres, M. F., Aloe, F., Lotufo Neto, F., \& Koenig, H. G. (2008). Versão em português da Escala de Religiosidade da Duke: DUREL. Archives of Clinical Psychiatry (São Paulo), 35(1), 31-32. https://doi.org/10.1590/ S0101-60832008000100006

Pillow, D. R., Malone, G. P., \& Hale, W. J. (2015). The need to belong and its association with fully satisfying relationships: A tale of two measures. Personality and Individual Differences, 74, 259-264. https://doi.org/10.1016/j.paid.2014.10.031

R Core Team. (2019). R: A language and environment for statistical computing. Vienna, Austria: R Foundation for Statistical Computing. Retrieved from https://www.r-project.org/.

Ritter, R. S., Preston, J. L., \& Hernandez, I. (2013). Happy tweets: Christians are happier, more socially 
connected, and less analytical than atheists on twitter. Social Psychological and Personality Science, 5(2), 243249. https://doi.org/10.1177/1948550613492345

Schubert, T. W., \& Otten, S. (2002). Overlap of self, ingroup, and outgroup: Pictorial measures of self-categorization. Self and Identity, 1(4), 353-376. https://doi.org/10.1080/152988602760328012

Seppala, E. M., Rossomando, T., \& Doty, J. R. (2008). Social connection and compassion: Important predictors of health and well-being. Social Research, 80(2), 411-430.
Sun, J., Harris, K., \& Vazire, S. (2019). Is well-being associated with the quantity and quality of social interactions? American Psychologist, 20(9), 714-715. https://doi.org/10.1037/h0021466

Tomasello, M. (2014). The ultra-social animal. European Journal of Social Psychology, 44, 187-194. https://doi. org/10.1002/ ejsp.2015

Recebido em: 11/01/2019

Reformulado em: 19/12/2019

Aprovado em: 10/03/2020 


\section{Appendix}

Portuguese version of the social connectedness scale (SCS)

Utilize as opções de resposta abaixo para informar o quanto que cada uma das frases à esquerda é verdadeira para você e te descreve bem. A escala vai de "Discordo totalmente" a "Concordo totalmente".

Itens $\begin{gathered}\text { Discordo } \\ \text { totalmente }\end{gathered}$ Discordo Não sei $\quad$ Concordo $\begin{gathered}\text { Concordo } \\ \text { totalmente }\end{gathered}$

1. Eu realmente me sinto aceito

(a) por outros em minha vida.

2. Muitas vezes, eu não me sinto vinculado (a) afetivamente com os outros.

3. Existem várias ocasiões em que estou acompanhado de um grupo de amigos e não me sinto completamente vinculado (a) a eles.

4. Eu sinto um forte sentimento de vínculo quando estou com os meus amigos.

5. Existem lugares que vou onde me sinto vinculado afetivamente com os outros.

6. Eu sinto que existem muitas pessoas com quem eu tenho um vínculo afetivo.

7. Quando estou com a minha família, sinto que tenho um vínculo afetivo com eles. 
About the authors:

André L. A. Rabelo é Mestre e doutor em Psicologia. Pesquisador Colaborador do Programa de Pós-Graduação em Psicologia Social, do Trabalho e das Organizações (PSTO) da Universidade de Brasília (UnB). Criador do canal Minutos Psíquicos no YouTube. Desenvolve pesquisas na área de cognição social investigando temas como solidão, conectividade social, moralidade, crenças religiosas, crenças em teorias conspiratórias e em notícias falsas.

ORCID: https://orcid.org/0000-0001-5236-7574

E-mail: andreluiz.arabelo@gmail.com

Ronaldo Pilati é Doutor em Psicologia. Professor Associado da Universidade de Brasília (UnB). Pesquisador do Departamento de Psicologia Social e do Trabalho (PST). Realiza pesquisas na área de cognição social investigando temas como moralidade, comportamento desonesto, jeitinho, crenças científicas e pseudocientíficas.

ORCID: http://orcid.org/0000-0003-2982-5033

E-mail: rpilati@gmail.com

\section{Contact:}

andreluiz.arabelo@gmail.com 